\title{
DISKURSUS URGENSI CARBON EMISSION DISCLOSURE PADA PERUSAHAAN PERUSAHAAN PUBLIK DI INDONESIA
}

\author{
Umi Hanifah \\ Universitas Muhammadiyah Surakarta \\ banifahumi80@gmail.com \\ Wahyono \\ Universitas Muhammadiyah Surakarta \\ wabyonoums@gmail.com
}

\begin{abstract}
This article explores the implementation and importance of carbon emission disclosure by public companies in Indonesia. The study is conducted by reviewed related literatures and previous research as references. The study concludes that public companies in Indonesia have already disclosed carbon emission in their financial statements. However, the disclosure has not conducted in optimal manner. Those indicate that there are some actions already taken by them to response the global climate changes, especially the information about climate changes in Indonesia. Disclosure on carbon emission by public companies in Indonesia had positive impacts on the companies' image.
\end{abstract}

Keywords: Social Responsibility, Carbon Emission Disclosure, public companies 


\begin{abstract}
Abstrak
Artikel ini berusaha menjelaskan implementasi dan pentingnya carbon emission disclosurepada perusahaan-perusabaan publik di Indonesia. Kajian pada artikel ini dilakukan dengan studi pustaka dengan mengacu pada sejumlah referensi dan telaah hasil penelitian-peneltian terdahulu. Hasilnyamenunjukean bahwa Perusahaan-perusahaan publik di Indoensia sudah mengungkapkan emisi karbon dalam laporan tabuan perusahaan, walau belum sepenubnya optimal. Hal ini mengindikasikan bahwasebuah tindakan responsif telah dilakukan perusahaan-perusahaan publik dalam menghadapi perubahan iklim khususnya terkait denganinformasi peningkatan perubahan iklim yang ada di Indonesia.Tindakan pengungkapan berdampak memberikan citra positif perusahaan kepada publik
\end{abstract}

Kata kunci: Tanggung Jawab sosial, Carbon Emission Disclosure, Perusabaan Publik.

\title{
A. Pendahuluan
}

Menurut Friedman tanggung jawab sosial dulunya merupakan satu-satunya tanggung jawabperusahaan dimana perusahaan hanya meningkatkan keuntungan bagi pemegang saham, mungkin benar secara konteks pada tahun 1960an atau 1970an. ${ }^{1}$ Hal ini disebabkan dulunya semboyan klasik yang diterapkan oleh banyak korporasi yaitu "waktu adalah uang", menganggap bahwa tujuan utama perusahaan adalah memenuhi kebutuhan pribadi atau perusahaan dengan mengejar keuntungan secara total. Sejalan dengan pernyataan Friedman, pokok utama tanggung jawab (sosial) perusahaan pada kala itu hanya terpacu pada profit maximation atau disebut juga dengan istilah single bottom line. Hal tersebutdidasarkan pada pemikiran filosofi dualism yang kecenderungan berfikir secara konvensional, yaitu korporasi hanya bertugas untuk mencari keuntungan. Setelah mendapat keuntungan,

${ }^{1}$ MiltonFriedman, "The Social Responsibility of Business is to Increase its Profits", The New York Times Magazine, 1 September 1970, http://www. colorado.edu/studenggroups/libertarians /issues/friedman-soc-resp-business. html 
korporasi baru memperhatikan persoalan sosial. Sifat tamak (profit maximization) dari korporasi yang sulit dikontrol oleh hukum inilah salah satu problematika dari pemikiran filosofis. Pada kondisi seperti apa korporasi akan menentukan bahwa keuntungannya telah cukup, dan waktunya untuk perhatian terhadap persoalan sosial, adalah tidak dapat diperkirakan. Secara teoritik, pendiri perusahaan akan membuat kontrak kerjasama mendirikan korporasi dengan tujuan dan maksud secara individualistik (privately). Maksud yang terkandung didalamnya yaitu para pendiri hanya memberikan amanat kepada direksi sesuai dengan keinginan dan tujuan pendirian korporasi yang berfokus pada profit oriented. ${ }^{2}$

Namun kondisi saat ini telah berubah. Masyarakat dunia telah menyadari adanya ketimpangan sosial dan kemalangan yang dididerita sebagian lainnya dan akan mempunyai ekspektasi yang berbeda terhadap korporasi. ${ }^{3}$ Bisnis bukan lagi sebagai entitas yang hanya mementingkan dirinya sendiri, melainkan wajib melakukan adaptasi kultural dengan lingkungan. ${ }^{4}$ Ketika perusahaan hanya berfokus pada keuntungan, maka kemungkinan besar bisnis akan cenderung menyimpang. Pencemaran lingkungan dan sikap tidak peduli terhadap masyarakat sekitar adalah salah satu penyimpangan yang sering terjadi. Dengan begitu tanggung jawab sosial dari perusahaan sangat dibutuhkan. Perubahan lingkungan yang dinamis, baik dipicu oleh kekuatan eksternal maupun kekuatan internal telah memaksa para pelaku bisnis untuk tidak saja harus selalu meningkatkan laba dan kinerja, tetapi juga mesti peduli terhadap problem sosial.

Entitas bisnis sekarang ini bukan hanya menerapkan prinsip single bottom line saja, melainkan harus menerapkan prinsip

\footnotetext{
${ }^{2}$ AlanWolfe. "The Modern Corporation: Private Agent or Public Actor?", Washington and Lee Law Review 50 (Fall, 1993), hlm. 1683

${ }^{3}$ MuktiFajar. Tanggung Jawab Sosial Perusahaan di Indonesia.(Yogyakarta: Pustaka Pelajar, 2013), hlm. 100.

${ }^{4}$ Mas AchmadDaniri. StandarisasiTanggungJawabSosial Perusahaan. SambutanMenteri NegaraLingkunganHiduppada Seminar Sehari "A Promise ofGold Rating: Sustainable CSR". Tanggal 23 Agustus2006.hal.3.diambildari www. menlh.go.id. Diaksespadatanggal 23 Mei 2018
} 
triple bottom line. John Elkington pada tahun 1997 melalui bukunya Cannibals with Forks, the Triple Bottom Line of Twentieth Century Business telah mempopulerkan istilah triple bottom line. Pandangan Elkington menyatakan bahwa perusahaan yang ingin berkelanjutan haruslah memperhatikan 3 P (profit, people, planet). Selain mencari profit tentunya, perusahaan harus memperhatikan dan terlibat pada pemenuhan kesejahteraan masyarakat (people), serta turut berkonstribusi aktif dalam menjaga kelestarian lingkungan (planet). Dalam pandangan tersebut perusahaan harus memperhatikan aspek sosial dan lingkungan selain aspek ekonomi. ${ }^{5}$

Penerapan prinsiptriple bottom linepada perusahaa menyatakan bahwaselain melaporkan aspek keuangan, perusahaan juga melaporkan aspek kepedulian sosial dan upaya pelestarian lingkungan hidup. ${ }^{6}$ Fenomena inilah yang menyulut wacana corporate social responsibility (CSR) yang menekankan bahwa tanggung jawab perusahaan bukan lagi sekadar aktifitas ekonomi (menciptakan profit demi kelangsungan bisnis), melainkan juga termasuk tanggung jawab sosial termasuk lingkungan. ${ }^{7}$ CSR merupakan wacana yang semakin dikenal dalam dunia bisnis di Indonesia, fenomena ini diakibatkan oleh mengglobalnya tren praktek CSR dalam bisnis. ${ }^{8}$ Sebagai salah satu pendekatan sukarela yang berada pada tingkat beyond compliance, penerapan CSR saat ini berkembang pesat termasuk di Indonesia sebagai respon dunia usaha yang melihat aspek sosial dan lingkungan sebagai peluang untuk meningkatkan daya saing serta sebagai bagian dari pengelolaan resiko, menuju sustanaibility dari kegiatan usahannya. ${ }^{9}$ Secara singkat makna CSR adalah perusahaan memiliki tugas moral jujur, mematuhi hukum,

${ }^{5}$ Nurdizal M.Rachman. Panduan Lengkapp Perencanaan CSR. (Jakarta: Niaga Swadaya, 2011), hlm. 3.

${ }^{6}$ Muh.AriefEffendi.The Power of Good Corporate Governance TeoridanImplementasi. (Jakarta: SalembaEmpat, 2016), hlm. 5

Dwi Kartini. Corporate Social Responsibility: Tranformasi Konsep Sustainablity Management dan Implementasi di Indonesia. Bandung: Refika Aditama, 2013 hal. 12.

${ }^{8}$ Soraya Fitria dan Dwi Hartanti, "Islam Dan Tanggung Jawab Sosial : Studi Perbandingan Pengungkapan Berdasarkan Global Reporting Initiative Indeks dan Islamic Social Reporting Indeks". (Purwokerto: Simposium Nasional Akuntansi 13, 2010), hlm. 1.

${ }_{9}$ Dwi Kartini. Corporate Social Responsibility... hlm. 13. 
menjunjung tinggi integritas dan tidak korupsi. CSR menekankan bahwa perusahaan harus mengembangkan praktik bisnis yang etis dan sustainable, secara ekonomi, sosial dan lingkungan. ${ }^{10}$ Tidak mengherankan kalau kemudian CSR dianggap sebagai jawaban terhadap praktik bisnis yang mencari untung sebesar-besarnya. Bahkan sementara kalangan menganggap bahwa CSR dianggap sebagai beban yang mengganggu konsentrasi perusahaan untuk memaksimalkan nilai bagi stakeholder.

Terkait dengan CSR, isu yang sedang menjadi topik perbincangan di berbagai penjuru dunia dalam pengeloaan sumberdayaalam adalah isu global warming. Dimana berbagai kalangan masyarakat dunia mulai peduli terhadap Iingkungan mereka dan berbagai macam cara mereka lakukan untuk memperbaiki kerusakan alam. Kesadaran masyarakat terhadap lingkungan mulai tumbuh dan berkembang di semua negara. ${ }^{11}$ Puncaknya, ditandatanganilah Protokol Kyoto oleh beberapa negara di dunia, yang merupakan sebuah amandemen terhadap Konvensi Rangka Kerja PBB tentang Perubahan lklim (United Nation Framework Convention on Climate Change/UNFCCC). ${ }^{12}$

Indonesia telah meratifikasi Protokol Kyoto melalui UU No. 17 Tahun 2004 dalam rangka melaksanakan pembangunan berkelanjutan serta ikut serta dalam upaya menurunkan emisi Gas Rumah Kaca (GRK) global. Indonesia berkomitmen untuk mengurangi emisi karbon dapat dilihat pada pasal 4 Perpres No. 61 Tahun 2011, yang menyebutkan bahwa pelaku juga ikut andil dalam upaya penurunan emisi GRK. Upaya pengungkapan emisi GRK (termasuk emisi karbon) yang dilakukan oleh perusahaan sebagai pelaku usaha dapat diketahui dari pengungkapan emisi

\footnotetext{
${ }^{10}$ WesleyCragg, Mark S Schwartz,and David Weitzner. Corporate Sosial Responsibility. (New York: Routledge, 2016), hlm. 7.

${ }^{11}$ S. Dwijayanti. Manfaat Penerapan Carbon Accounting di Indonesia. Jurnal Akuntansi kontemporer, Vol 3, No.1, 2011, hlm 80.

${ }^{12}$ Kardono. Memahami Perdagangan Karbon. Info PUSTANLING, Volume 12 No. 1, 2010, hlm. 3.
} 
karbon (Carbon Emission Disclosure). ${ }^{13}$ Peraturan Pemerintah No. 47 Tahun 2012 juga menegaskan PT untuk melakukan tanggung jawab sosial dan lingkungan atas segala aktifitas operasinya ${ }^{14}$.

Di Indonesia praktek pengungkapan tanggung jawab sosial diatur oleh Ikatan Akuntan Indonesia (IAI). PSAK No.1 paragraf 9 secara implisit menyarankan untuk mengungkapkan tanggung jawab sosial mengenai masalah lingkungan dan sosial. Oleh karena itu, pengguna laporan keuangan tidak terbatas pada sebagian shareholder, namun meluas keseluruhan stakeholder lain seperti karyawan, pemasok, pelanggan, masyarakat dan lainnya.

Keberlanjutan perusahaan hanya akan terjamin apabila perusahaan memperhatikan dimensi sosial dan lingkungan hidup. Sudah menjadi fakta bagaimana resistensi masyarakat sekitar, diberbagai tempat dan waktu muncul kepermukaan terhadap perusahaan yang dianggap tidak memperhatikan aspek-aspeksosial, ekonomi dan lingkungan hidupnya. Emission Carbon Disclosure setidaknya menunjukkan peran penting dalam meningkatkan nilai perusahaan sebagai hasil dari peningkatan penjualan dan profitabilitas melalui loyalitas konsumen yang terbangun dengan cara pelaksanaan kegiatan sosial di lingkungannya. Oleh karena itu, dibutuhkan acuan (guideline) untuk mengukur sejauh mana perusahaan membuat laporan tanggung jawab sosial yang turut menyajikan aspek-aspek carbon emission.

Berdasarkan dari pemaparan diatas, artikel ini berusaha mengeksplorasi pentingnya pengungkapan carbon emission disclosure pada perusahaan perusahaan publik di Indonesia. Diskursus ini mendasarkan kajiannya dengan menelusur referensi ataupun teori yang relevan dengan topik yang ditemukan dan ditentukan. Referensi teori diperoleh dengan jalan kajian studi literatur dan

\footnotetext{
${ }^{13}$ R. Jannah, R. dan D. Muid."Analisis Faktor-Faktor Yang Mempengaruhi Carbon Emission Disclosure Pada Perusahaan Di Indonesia."Diponegoro Journal Of Accounting, Vol. 3, No. 2, 2014, hlm. 1.

${ }^{14}$ Achmad LamoSaid,Corporate Social Responsibility dalam Perspektif governance. (Yogyakarta: V Budi Utama., 2015), hlm. 22.
} 
dijadikan sebagai fondasi dasar utama. Analisis deskriptif dilakukan dengan cara mendeskripsikan fakta-fakta yang kemudian tidak hanya menguraikannya saja tetapi memberikan pemahaman dan penjelasan secara detail.

\section{B. Pembahasan}

\section{Teori Stakeholder}

Pertama kalinya Freedman mengembangkan konsep stakeholder untuk menjelaskan tentang tingkah laku perusahaan (corporate behaviour) dan kinerja sosial. ${ }^{15}$ Stakeholder merupakan pihak berkepentinganperusahaan yang dapat mempengaruhi atau dipengaruhiaktivitas perusahaan, siapa saja stakeholdertersebut antara lain masyarakat, karyawan, pemerintah, supplier, pasar modal dan lain-lain. ${ }^{16}$

Tujuan teori stakeholderadalah untuk menciptakan nilai tambah bagi stakeholder karena telahmendukungkeberlangsungan hidup perusahaan. Stakeholderbisa saja tidak mendukung akan kebutuhan sumber daya yang diperlukan perusahaan, apabila perusahaan tidak memberikan perhatian kepada stakeholder. Oleh karena itu, perlu adanya pengelolaan stakeholder yang baik agar perusahaan mendapat dukungan penuh dan tujuan yang ingin dicapai perusahaan dapat digenggam. Pelaporan lingkungan berperan untuk menghindari setiap tindakan yang merugikan perusahaan.

\section{Teori Legitimasi}

Fokus dari teori legitimasi adalah pada interaksi antara perusahaan dengan lingkungan masyarakat. ${ }^{17}$ Teori legitimasi

\footnotetext{
${ }^{15}$ Ghomi and Leung, 2013. An Empirical Analysis of The Determinants of Greenhouse Gas Voluntary Disclosure in Australia. Accounting and Finance Research, Vol. 2 No. 1, 2013, hlm. 111.

${ }^{16}$ R. Gray. 2001. "Thirty Years of Social Accounting, Reporting, and Auditing: what (if anything) have we learnt?."Business Ethics: A European Review, Vol. 10, No.1, 2001 hlm. 10.

${ }^{17}$ ImamGhozali dan Anis Chariri. Teori Akuntansi. (Badan Penerbit Universitas Diponegoro. Semarang. 2007), hlm. 41.
} 
menyatakan kegiatan perusahaan didasarkan dan disesuaikan dengan konsep, nilai kepercayaan, dan ketentuan sosial yang dimiliki oleh masyarakat serta menjelaskan perlunya perusahaan menunjukkan tujuannya yang sejalan dengan masyarakat.

Teori legitimasi mendorong perusahaanmelakukan tanggungjawab kepada lingkungan agar terlihat legitimate di masyarakat. Perusahaan cenderungakan bertindak sesuai keinginan masyarakat yaitu bertanggung jawab terhadap lingkungan. Masalah lingkungan yang timbul karena operasi perusahaan tidak hanya berdampak pada lingkungan sekitar perusahaan, namun berkembang pada pemanasan global. Salah satu bentuk tanggungjawab lingkungan yang dilakukan perusahaan adalah dengan pengungkapan emisi. Ancaman legitimasi sebuah perusahaan akan menarik perusahaan untuk memasukkan lebih banyak informasi tanggung jawab sosial dalam laporan tahunan. Namun, kenyataan yang ada banyak perusahaan melakukan pengungkapan hanya untuk memperoleh legitimate dari masyarakat untuk bertahan hidup. Pengungkapan informasi emisi karbon pada laporan keuangan adalah salah satu cara perusahaanmembangun, mempertahankan, dan melegitimasi kontribusi perusahaan dari sisi ekonomi dan politis.

\section{Corporate Social Responsibility}

World Business Council on Suistainable Development (WBCSD) menyatakan CSR merupakan komitmen perusahaan melaksanakan etika keprilakuan (behavioral etchics) dan konstribusi untuk perkembangan ekonomi berkelanjutan (sustainable economic development) serta meningkatkan kualitas hidup karyawan dan keluarganya, komunitas lokal, serta masyarakat luas. ${ }^{18}$ Harmonisasi perusahaan dengan masyarakat sekitar dapat tercapai dengan komitmen manajemen puncak (top management) terhadap

${ }^{18}$ Muh. Arief Effendi. The Power of Good Corporate Governance TeoridanImplementasi. (Jakarta: SalembaEmpat, 2016), hlm. 78. 
penerapan CSR sebagai wujud akuntabilitas perusahaan dalam mengaplikasikan GCG.

Pengungkapan CSR digunakan perusahaan untuk mengungkapkan informasi berkaitan dengan kegiatan perusahaan dan pengaruhnya terhadap kondisi sosial masyarakat dan lingkungan. ${ }^{19}$ Pada era sekarang ini kesadaran akan pelaksanaan CSR menjadi penting seiring dengan maraknya kepedulian masyarakat terhadap produk ramah lingkungan. Mengingat salah satu prinsip GCG terkait pertanggungjawaban adalah kesesuaian dalam pengelolaan perusahaan terhadap peraturan perundanganundangan yang berlaku dan prinsip-prinsip korporasi yang sehat. ${ }^{20}$ menyatakan tujuan CSR adalah untuk meningkatkan citra perusahaan \& memegang asumsi bahwa perilaku perusahaan baik secara asasi.

CSR begitu penting sekarang ini adalah, konsumen menaruh perhatian lebih pada perusahaan yang memiliki tanggung jawab sosial. Konsumen terkadang rela mengeluarkan uang lebih untuk produk-produk perusahaan yang menyertakan kampanye sosial atau perlindungan lingkungan dalam pemasarannya. Selanjutnyaanjuran pemerintah akan pentingnya aktifitas CSR dan mengkomunikasikannya melalui laporan tahunan merupakan alasan berikutnya perusahaan melakukannya. Alasan pemerintah begitutertarik terhadap CSR adalah upaya masing-masing bisnis dapat membantu untuk memenuhi tujuan kebijakan yang dibuat, namun juga terkait pembangunan berkelanjutan dan perlindungan lingkungan. Begitu juga dengan kebutuhan perusahaan akan komunikasi CSR. Komunikasi CSR digunakan untuk penghubung perusahaan dengan stakeholder. Komunikasi CSR bertujuan membangun citra positif perusahaan.

\footnotetext{
${ }^{19}$ ImamGhozali dan Anis Chariri. Teori Akuntansi....hlm. 90.

${ }^{20}$ Ahmed RiahiBelkaoni,. Teori Akuntansi. (Jakarta: Salemba Empat, 2000), hlm. 44.
} 


\section{Disclosure}

Disclosureadalah pengungkapan informasi perusahaan baik yang kuantitatif maupun kualitatif, wajib atau sukarela, bersifat retrospektif ataupun prospektif serta tindakan yang bertujuan meningkatkan efektivitas pengungkapan serta untuk melakukan evaluasi manajemen oleh investor/stakeholder. ${ }^{21}$ Disclosure dalam laporan keuangan perusahaan mengandung makna bahwa informasi yang disajikan akan membantu investor dan stakeholder untuk mendapatkan informasi dalam menilai kinerja manajemen dan memutuskan investasi. 22

Standar Akuntansi Keuangan (SAK) 2012 nomor 1 tentang penyajian laporan keuangan, paragraf 70 menyatakan bahwa informasi yang disajikan dalam laporan keuangan harus berprinsip full disclosure. Jenis informasi yang diungkapkan dibagi menjadi dua, yaitu; mandatory dan voluntary disclosure. ${ }^{23}$ Mandatory disclosure merupakan pengungkapan informasi yang dilakukan untuk memenuhi ketentuan-ketentuan yang tercantum dalam undangundang, standar akuntansi dan peraturan pasar modal. Voluntary disclosuremerupakan pengungkapan informasi sukarela tanpa adanya kewajiban yang mengatur. Pengungkapan ini bermanfaat sebagai alat komunikasi manajemen dengan stakeholder.Tujuan perusahaan mengungkapkan informasi sukarela adalah untuk memperbaiki kesalahan, menaikkan likuiditas, merubah komposisi pemegang saham, mengantisipasi intervensi politik dan aturan serta untuk memperoleh keunggulan kompetitif.

Berdasar uraian tersebut, dapat disimpulkanvoluntary disclosureadalah informasi tambahan untuk kepentingan stakeholders yang bermanfaat untuk melengkapi informasi wajib (mandatory disclosure). Voluntary disclosure bermanfaat untuk mengurangi

${ }^{21}$ Paul M.Healy and Krishna G. Palepu, The Effect of Firms' Financial Disclosure Strategies on Stock Prices, Accounting Horizons, Vol. 7, No. 1, 1993, hlm. 5.

${ }^{22}$ E.S. Hendriksen, dan M. F. Van Breda. Accounting Theory, $5^{\text {th }}$ Edition (Singapore: Irwin-McGraw-Hill, 2001), hlm. 833

${ }^{23}$ William R Scott. Financial Accounting Theory. Edisi 6(New Jersey: Prentice Hall, 2012), hlm. 15-17. 
asymmetric information (kesenjangan informasi) antara perusahaan dan investor ${ }^{24}$. Voluntary disclosure diklasifikasikan menjadi 3 jenis informasi, yaitu; informasi strategis masa depan perusahaan, informasi keuangan, informasi non keuangan termasuk pelaporan keuangan ${ }^{25}$.

Bentuk pengungkapan sukarela salah satunya adalah pengungkapan lingkungan. Pengungkapan lingkungan adalah informasi yang berhubungan atas dampak kegiatan masa lalu, saat ini dan masa depan dalam pengelolaan lingkungan sebagai akibat dari adanya kegiatan operasi perusahaan ${ }^{26}$. Berdasarkan definisi di atasdapat disimpulkan bahwa pengungkapan lingkungan merupakan proses penyebaran informasi tambahan kepada stakeholder terkait dampak atas kegiatan operasional perusahaan terhadap lingkungan.

\section{Emisi Karbon}

Gas alam adalah bahan bakar fosil yang tidak dapat diperbaharui, seperti minyak dan batubara, yang mana terbentuk dari tumbuhan, binatang dan mikroorganisme yang hidup jutaan tahun silam yang tertimbun di lapisan bawah laut ${ }^{27}$. Definisi emisi karbon adalah pelepasan karbon ke atmosfer bumi. Pelepasan terjadi karena adanya pembakaran terhadap karbon, baik dalam bentuk tunggal maupun senyawa. Menurut Kementerian Lingkungan Hidup (2012) gas-gas ini dapat berbentuk CO2, CH4, N2O, HFCs, C4F9OC2H5, CHF2OCF2OC2F4OCHF2 dan sebagainya. Emisi karbon terkait emisi gas rumah kaca; kontributor

\footnotetext{
${ }^{24}$ Botosan, Disclosure Level and The Cost of Equity Capital. The Accounting Review Vol.7, No.3, July 1997, hlm. 324.

${ }_{25}$ G.K Meek, B. Roberts Clare and Sidney. J. Gray., "Factors Influencing Voluntary An-nual Report Disclosure by U.S., U.K. and Continental European Multinational Corpo-rations", Journal of International Business Studies, Vol. 26, No. 3, 1995,hlm. 556.

${ }^{26}$ T. D. Wilmshurst and G. R. Frost. Corporate environmental reporting: a test of legitimacy theory. Accounting, Auditing \& Accountability Journal, 13 (1), 2000, hlm. 12.

${ }^{27}$ Sutarno. Sumber Daya Energi. Edisi 1, Cetakan ke-1. (Yogyakarta: Graha Ilmu, . 2013), hlm. 28.
} 
utama perubahan iklim. Penyebab perubahan iklim salah satunya adalah emisi global yang lepas diudara yang menyebabkan dampak gas rumah kaca. Gas rumah kaca yang disepakati dalam Protocol Kyoto, yaitu karbondioksida $\left(\mathrm{CO}_{2}\right)$, metana $\left(\mathrm{CH}_{4}\right)$, nitrotiga Oksida $\left(\mathrm{N}_{2} \mathrm{O}\right)$, chloro-flouro-carbon (CFC), hidro-flouro-carbon (HFCs), dan sulfur heksafluorida (SF).

Gas $\mathrm{CO}_{2}$ merupakan penyebab utama pemanasan global. Jumlah pelepasan $\mathrm{CO}_{2}$ dari hari ke hari terus meningkat baik tingkat global, regional, nasional pada suatu negara maupun lokal untuk suatu kawasan. Hal ini dikarenakan adanya peningkatan pembakaran bahan bakar minyak, batu bara dan bahan-bahan organik lainnya yang melampaui batas tumbuhan dan laut untuk menyerapnya, sehingga peningkatan suhu permukaan bumi dan perubahan iklim yang sangat ekstrim dibumi terjadi. Aktifitas yang banyak menghasilkan CO2 adalah sektor industri dan energi. Pengurangan emisi adalah salah satu upaya menjaga bumi dari kerusakan akibat kegiatan operasi perusahaan ${ }^{28}$.

\section{Pengungkapan Emisi Karbon}

Pengungkapan karbon merupakan salah satu jenis pengungkapan lingkungan. ${ }^{2}$ Pengungkapan lingkungan adalah bagian dari laporan tambahan yang sudah dinyatakan dalam PSAK No. 1 (Revisi 2009). Salah satu cara mendapatkan legitimasi, perusahaan dapat melakukan pengungkapan akan aktifitas perusahaannya ke publik ${ }^{30}$. Pengungkapan lingkungan mencakup intensitas emisi GHG atau gas rumah kaca dan penggunaan energi, corporate governance dan strategi dalam kaitannya dengan dampak perubahan iklim.

\footnotetext{
${ }^{28}$ RubijantoSiswosoemarto. Intelejen Ekonomi: Teori dan Aplikasi. (Jakarta: PT Gramedia Pustaka Utama), 2012, hlm. 33

${ }_{29}$ M. M. S. Najah, "Carbon risk management, carbon disclosure and stock market effects: An international perspective. "Doctor of Philosophy, University of Southern Queensland, Australia.Diakses 26 Maret 2015.

${ }^{30}$ Uyar et al. Association Between Firm : Evidence from Turkish Listed Companies. Intangible Capital, Vol. 9(4), 2013, hlm. 1082.
} 
Perusahaan dituntut lebih terbuka dengan informasi terkait semua aktivitas perusahaan dan bentuk pertanggungjawabannya. Perusahaan yang mengungkapkan informasi dalam laporan tahunannya telah memperlihatkan transparansi dan akuntabilitasnya. Informasi-informasi yang diungkapkan dalam laporan tahunan dapat dikelompokkan menjadi dua yaitu mandatory disclosure dan voluntary disclosure ${ }^{31}$. Pengungkapan wajib merupakan pengungkapan minimum yang disyaratkan pada standar akuntansi yang berlaku (peraturan mengenai pengungkapan laporan keuangan yang dikeluarkan oleh pemerintah melalui keputusan ketua BAPEPAM No.SE-02/PM/2002). Sedangkan pengungkapan sukarela merupakan pilihan bebas suatu manajemen perusahaan untuk memberikan informasi akuntansi dan informasi lainnya yang dipandang relevan para pemakai laporan keuangan. Umumnya, perusahaan melakukan mengungkapkan informasi jika informasi tersebut dapat meningkatkan nilai perusahaan.

Pengembangan pengungkapan emisi karbon menggunakan indeks pengungkapan yang didesain berdasar konstruksi dari faktor-faktor yang terindentifikasi dalam information request sheet yang telah dikembangkan oleh CDP (Carbon Disclosure Project) ${ }^{32}$. CDP merupakan lembaga independen non-profit yang menyediakan informasi terkait perubahan iklim di dunia yang memiliki 3000 organisasi di 60 negara $^{33}$. Pengungkapan CDP dapat dibagi menjadi 5 kategori yaitu; perubahan iklim, emisi gas rumah kaca, konsumsi energi, pengurangan gas rumah kaca, dan emisi karbon. Berikut terkait indeks pengungkapan emisi karbondalam tabel 1.

${ }^{31}$ M.N. Darrough, "Disclosure Policy and Competition: Courtnot vs Bertrand.” The Accounting Review, Vol.68 No.3, 2013, hlm. 535.

${ }^{32}$ Choi,Bo Bae, LeeDoowon and Jim Psaros. 2013. "An Analysis of Australian Company Carbon Emission Disclosures." Pasific Accounting Review Journal, Vol. 25, hlm.65.

${ }^{33}$ Ibid. 
Tabel 1

Indeks Pengungkapan Emisi Karbon

\begin{tabular}{|c|c|}
\hline Kategori & Item \\
\hline $\begin{array}{l}\text { Perubahan iklim: Risiko dan } \\
\text { peluang (Climate Change) }\end{array}$ & $\begin{array}{l}\text { CC-1:Penilaian/deskripsi terhadap risiko } \\
\text { (peraturan/regulasi baik khusus } \\
\text { maupun umum) yang berkaitan } \\
\text { dengan perubahan iklim dan tindakan } \\
\text { yang diambil untuk mengelola resiko } \\
\text { tersebut. } \\
\text { CC-2:Penilaian/deskripsi saat ini (dan masa } \\
\text { depan) dari implikasi keuangan, } \\
\text { bisnis dan peluang dari perubahan } \\
\text { iklim. }\end{array}$ \\
\hline $\begin{array}{l}\text { Emisi Gas Rumah Kaca } \\
\text { (GHG/Green House Gas) }\end{array}$ & $\begin{array}{c}\text { GHG-1:Deskripsi metodologi yang } \\
\text { digunakan untuk menghitung emisi } \\
\text { gas rumah kaca (missal protocol } \\
\text { GRK atau ISO). } \\
\text { GHG-2: } \text { Keberadaan verifikasi eksternal } \\
\text { kuantitas emisi GRK oleh siapa } \\
\text { dan atas dasar apa. } \\
\text { GHG-3:Total emisi gas rumah kaca (metric } \\
\text { tin CO2-e) yang dihasilkan. } \\
\text { GHG-4:Pengungkapan lingkup 1 dan } 1 \text { atau } \\
\text { 3 emisi GRK langsung. } \\
\text { GHG-5:Pengungkapan emisi GRK } \\
\text { berdasarkan asal atau sumbernya } \\
\text { (misalnya: batu bara, listrik, dll). } \\
\text { GHG-6:Pengungkapan emisi } \\
\text { berdasarkan fasilitas atau level } \\
\text { segmen. }\end{array}$ \\
\hline
\end{tabular}




\begin{tabular}{|c|c|}
\hline $\begin{array}{l}\text { Konsumsi energi (EC/ } \\
\text { Energy Consumtion) }\end{array}$ & $\begin{array}{l}\text { EC-1:Jumlah energy yang dikonsumsi } \\
\text { (misalnya: tera-joule PETA-joule). } \\
\text { EC-2:Kuantifikasi energi yang digunakan } \\
\text { dari sumber daya yang dapat } \\
\text { diperbaruhi. } \\
\text { EC-3:Pengungkapan menurut jenis, fasilitas } \\
\text { atau segmen. }\end{array}$ \\
\hline $\begin{array}{l}\text { Pengurangan Gas Rumah } \\
\text { Kaca dan Biaya (RD/ } \\
\text { Reduction and Cost) }\end{array}$ & $\begin{array}{l}\text { RC-1:Detail/rincian dari rencana atau strategi } \\
\text { untuk mengurangi emisi GRK. } \\
\text { RC-2:Spesifikasi dari target tingkat/level dan } \\
\text { tahun pengurangan emisi GRK. } \\
\text { RC-3:Pengurangan emisi dan biaya atau } \\
\text { tabungan (cost or savings) yang dicapai } \\
\text { saat ini sebagai akibat dari rencana } \\
\text { pengurangan emisi karbon. } \\
\text { RC-4:Biaya emisi masa depan yang } \\
\text { diperhitungkan dalam perencanaan } \\
\text { belanja modal (capital expenditure } \\
\text { planning). }\end{array}$ \\
\hline $\begin{array}{l}\text { Akuntabilitas Emisi Karbon } \\
\text { (AEC/ Accountability of } \\
\text { EmissionCarbon) }\end{array}$ & $\begin{array}{r}\text { AEC-1:Indikasi dimana dewan komite (atau } \\
\text { badan eksekutif lainnya) memiliki } \\
\text { tanggung jawab atas tindakan } \\
\text { yang berkaitan dengan perubahan } \\
\text { iklim. } \\
\text { AEC-2:Deskripsi mekanisme dimana dewan } \\
\text { (atau badan eksekutif lainnya) } \\
\text { meninjau kemajuan perusahaan } \\
\text { mengenai perubahan iklim. }\end{array}$ \\
\hline
\end{tabular}

Sumber: Choi,et al (2013)

Pada kategori kedua poin keempat $\left(\mathrm{GHG}_{4}\right)$ tabel 2 disebutkan mengenai ruang lingkup 1, 2, dan 3. Ruang lingkup ini menjelaskan tentang sumber emisi perusahaan, apakah secara langsung atau tidak langsung. 


\section{Tabel 2}

\section{Deskripsi Ruang Lingkup 1, 2, dan 3}

\begin{tabular}{|c|c|c|}
\hline Scope 1 & $\begin{array}{l}\text { Emisi GRK } \\
\text { langsung }\end{array}$ & $\begin{array}{l}\text { 1. Emisi GRK terjadi dari sumber atau } \\
\text { dikendalikan oleh perusahaan, misalnya: } \\
\text { emisi dari pembakaran, boiler, tungku, } \\
\text { kendaraan yang dimiliki perusahaan; } \\
\text { emisi dari produksi kimia pada peralatan } \\
\text { yang dimiliki dan dikendalikan oleh } \\
\text { perusahaan. } \\
\text { 2. Emisi } \mathrm{CO}_{2} \text { langsung dari pembakaran } \\
\text { biomassa tidak dimasukkan dalam } \\
\text { lingkup } 1 \text { tetapi dilaporkan secara } \\
\text { terpisah. } \\
\text { 3. Emisi GRK yang tidak terdapat pada } \\
\text { protocol Kyoto, misalnya CFC, NOX, } \\
\text { dll sebaiknya tidak dimasukkan dalam } \\
\text { lingkup } 1 \text { tetapi dilaporkan terpisah. } \\
\end{array}$ \\
\hline Scol & $\begin{array}{l}\text { Emisi GRK } \\
\text { secara tidak } \\
\text { langsung yang } \\
\text { berasal dari listrik }\end{array}$ & $\begin{array}{l}\text { 1. Mencakup emisi GRK dari pembangkit } \\
\text { listrik yang dibeli atau dikonsumsi oleh } \\
\text { perusahaan. } \\
\text { 2. Lingkup } 2 \text { secara fisik terjadi pada } \\
\text { fasilitas dimana listrik dihasilan. }\end{array}$ \\
\hline Scope 3 & $\begin{array}{l}\text { Emisi GRK tidak } \\
\text { langsung lainnya }\end{array}$ & $\begin{array}{l}\text { 1.Lingkup } 3 \text { adalah katergori pelaporan } \\
\text { operasional yang memungkinkan untuk } \\
\text { perlakuan semua emisi tidak langsung } \\
\text { lainnya. } \\
\text { 2. Lingkup } 3 \text { adalah konsekuensi dari } \\
\text { kegiatan perusahaan, tetapi terjadi } \\
\text { dari sumber yang tidak dimiliki atau } \\
\text { dikendalikan oleh perusahaan. } \\
\text { 3. Contoh lingkup } 3 \text { adalah kegitana } \\
\text { ektraksi dan produksi bahan baku yang } \\
\text { dibeli, transportasi dari bahan bakar } \\
\text { yang dibeli, dan penggunaan produk dan } \\
\text { jasa yang tidak dijual. }\end{array}$ \\
\hline
\end{tabular}

Sumber: Choi,et al (2013) 
Tabel 2 adalah ringkasan terkait ruang lingkup sumber emisi perusahaan, dimana ruang lingkup ini bermanfaat untuk menentukan apakah sumber emisi perusahaan dapat dimasukkan dalam kategori item $\mathrm{GHG}_{4}$ atau tidak.

\section{Telaah PenelitianTerkait Carbon Emission Disclosure}

Beberapa penelitian tentang carbon emission disclosure telah banyak dilakukan, dan penelitian tersebut menunjukkan hasil temuan yang berbeda-beda. Perbedaan hasil tersebut dimungkinkan karena lokasi penelitian yang berbeda atau pemilihan proksi yang berbeda. Jannah dan Muid menguji faktor-faktor yang mempengaruhi luas pengungkapan emisi karbon pada perusahaan di Indonesia. ${ }^{34} \mathrm{Hasil}$ penelitian menunjukkan bahwa media exposure, tipe perusahaan, profitabilitas, ukuran perusahaan, dan leverage berpengaruh terhadap pengungkapan emisi karbon di indonesia. Pradini menguji pengaruh sistem manajemen lingkungan bersertifikasi ISO 14001, keberadaan fungsi lingkungan, kesesuaian laporan informasi lingkungan berdasarkan GRI versi 3.1, peringkat PROPER, ukuran perusahaan, leverage, profitabilitas dan jenis industri terhadap luas pengungkapan emisi karbon pada perusahaan di indonesia. ${ }^{35} \mathrm{Hasil}$ penelitiannya menyatakan bahwa kesesuaian laporan informasi lingkungan dengan GRI versi 3.1, peringkat PROPER dan ukuran perusahaan berpengaruh signifikan terhadap luas pengungkapan emisi karbon. Kemudian penelitian yang telah menguji pengaruh antara karakteristik perusahaan dan carbon emission disclosure di luar Indonesia diantaranya, Lorenzo et al yang menganalisis faktorfaktor yang mempengaruhi perusahaan melakukan pengungkapan informasi terkait emisi gas karbon. ${ }^{36}$ Variabel penelitian diantaranya ukuran perusahaan, leverage, $\mathrm{ROA}, \mathrm{ROE}$ dan rasio market to book.

\footnotetext{
${ }^{34}$ R. Jannah dan D. Muid.“Analisis Faktor-Faktor ... hlm. 1.

${ }^{35}$ Pradini, H. S. 2013. "The Analysis of Information Content towards Greenhouse Gas Emissions Disclosure in Indonesia Companies". (Fakultas Ekonomika dan Bisnis, Universitas Diponegoro. 2013). hlm. 67.

${ }^{36}$ Jose-Manel Prado Lorenzo, Luiz Rodriguez-Dominguez, Isabel Gallego-Alvarez dan Isabel-Maria Garcia-Sanchez. 2009. Factors Influencing the Disclosure of Greenhouse Gas Emissions in Companies World-Wide. Journal of Management Decisions, Vol.47, hlm.1150.
} 
Hasil penelitian menyatakan bahwa adanya hubungan langsung antara ukuran perusahaan, kapitalisasi pasar dan pengungkapan informasi selain dari GRI. Chu et al menguji faktor-faktor pendorong pelaporan gas emisi oleh perusahaan di China. Hasil menunjukkan bahwa ukuran perusahaan dan tipe perusahaan mempengaruhi pengungkapan terkait gas emisi oleh perusahaan di China. ${ }^{37}$

Penelitian yang menguji pengaruh antara carbon emission disclosure dan nilai perusahaan telah banyak dilakukan.Chika Shika and Tomoki Oshikamenguji dampak emisi karbon perusahaan dan pengungkapan nilai perusahaan. Hasil penelitian menyatakan bahwa emisi karbon perusahaan memiliki hubungan negatif dengan nilai pasar ekuitas, pengungkapan manajemen karbon memiliki hubungan positif dengan nilai pasar ekuitas dan hubungan positif antara pengungkapan karbon dan nilai pasar ekuitas lebih kuat dengan volume emisi karbon yang lebih besar. ${ }^{38}$

Penelitian yang menguji pengaruh antara karakteristik perusahaan dan nilai perusahaan telah banyak dilakukan. Leni Astuti dan Erma Setiawatimenguji apakah profitabilitas, kebijakan deviden, kebijakan hutang, dan kepemilikan manajerial berpengaruh terhadap nilai perusahaan. Hasil penelitian menyatakan bahwa profitabilitas berpengaruh terhadap nilai perusahaan. ${ }^{39} \mathrm{Hasil}$ penelitian menyatakan bahwa profitabilitas berpengaruh terhadap nilai perusahaan. Djoko Suhardjanto dan Shinta menguji efek dari CSR disclosure pada nilai perusahaan di tahun disclosure dan setahun setelah CSR disclosure. Penelitian tersebut juga menggunakan jenis

${ }^{37}$ Chu, Choi Ieng, Bikram Chatterjee and Alistair Brown. The current status of greenhouse gas reporting by Chinese companies. "Managerial Auditing Journal”, Vol. 28 Iss 2, 2012,hlm. 125.

${ }^{38}$ Chika Shika and Tomoki Oshika. "Disclosure effects, carbon emissions and corporate value”. Management and policy journal, Vol.5 No.1, 2014, hlm. 33.

${ }^{39}$ Leni Astuti dan Erma Setiawati. "Analisis Pengaruh Profitabilitas, Kebijakan Deviden, Kebijakan Hutang, Dan Kepemilikan Manajerial terhadap Nilai Perusahaan (Studi Empiris Pada Perusahaan Manufaktur Yang Terdaftar Di Bursa Efek Indonesia Tahun 2010-2012)". Seminar Nasional dan Call For Paper. Program Studi Akuntansi-FEB UMS, 2014, hlm. 11. 
industri dan besarnya perusahaan sebagai variabel penyangga. ${ }^{40} \mathrm{Hasil}$ penelitian menunjukkan bahwa nilai perusahaan dipengaruhi oleh CSR di tahun itu dan setahun setelah disclosure. Penelitian juga menyatakan hasil bahwa hanya jenis industri yang mempengaruhi nilai perusahaan.

Febrianti menguji apakah nilai perusahaan dipengaruhi oleh pertumbuhan perusahaan, ukuran perusahaan, Debt to Equity rasio (DER), struktur aktiva, profitabilitas, likuiditas dan leverage $e^{41}$. Hasil penelitian menyatakan bahwa pertumbuhan perusahaan, ukuran perusahaan dan Debt to Equity rasio (DER) berpengaruh terhadap nilai perusahaan. Safitri dan Wijaya menguji pengaruh leverage, deviden payout ratio, earning per share dan kepemilikan manajerial terhadap nilai perusahaan. Hasil penelitian menunjukkan variabel earning per share berpengaruh positif terhadap nilai perusahaan ${ }^{42}$. Putri dan Raharja menguji pengaruh CSR terhadap nilai perusahaan dan pengaruh kepemilikan manajerial dalam hubungan antara CSR dengan nilai perusahaan. ${ }^{43}$ Hasil penelitian menyatakan bahwa nilai perusahaan dipengaruhi oleh CSR yang didorong dengan tingkat pengungkapan CSR dan kepemilikan manajerial memiliki pengaruh sebagai variabel moderasi yang memperlemah hubungan antara CSR terhadap nilai perusahaan.

Bertitik tolak dari berbagai penelitian-penelitian yang telah dilakukan oleh para peneliti terdahulu mempunyai hasil yang bervariatif. Namun demikian penelitian-peletian terkait lebih

${ }^{40}$ Suhardjanto, Djoko dan Shinta Nugraheni. "Pengaruh Corporate Social Responsibility (CSR) Disclosure terhadap Nilai Perusahaan (Studi Empiris di Bursa Efek Indonesia". Jurnal Akuntansi., Volume 16, Nomor 2, Tahun 2012 Fakultas Ekonomi Universitas Tarumanagara, 2012, hlm. 37.

${ }^{41}$ M. Febrianti. Faktor-Faktor yang Mempengaruhi Nilai Perusahaan pada Industri Pertambangan di Bursa Efek Indonesia. Jurnal Bisnis dan Akutansi, Vol.14 No.2, Agustus 2012, hlm. 143.

${ }^{42}$ Yancik Safitri dan Trisnadi Wijaya. 2015. Analisis Pengaruh Leverage Ratio, DPR, EPS dan Kepemilikan Manajerial terhadap Nilai Perusahaan. STIE MDP, 2015, hlm. 9.

${ }^{43}$ Hanni Chyntia MaitaPutri dan Surya Raharja. Pengaruh CSR terhadap Nilai Perusahaan dengan Kepemilikan Manajerial sebagai Variabel Moderating. “Diponegoro journal of accounting", Vol.2, No 3, Tahun 2013, hlm. 1. 
banyak berupa pengujian empiris untuk fokus secara kuantitatif daripada kualitatif, utamanya karakteristik perusahaan. Berdasar atas penelitan-penelitian terdahulu dapat diketahui bahwa pada dasarnya pengungkapan laporan tahunan entitas bisnis syariah sudah cukup akuntabel, tetapi dari unsur pengungkapan yang memperhatikan indeks carbon emission disclosuremasih belum ada satupun yang mencapai hasil yang benar benar maksimal.

\section{A. Simpulan}

Emisi karbon dan pengungkapan perubahan iklim sedang booming di berbagai negara, termasuk juga di Indonesia. Terkait dengan pelaporan dan kualitas mengenai emission carbon disclosure, sebagian besar perusahaan menggungkapkan hal tersebut bersifat deskriptif. Berdasar atas penelitan-penelitian carbon emission disclosure oleh para peneliti terdahulu dapat diketahui bahwa pada dasarnya pengungkapan laporan tahunan perusahaan-perusahaan publik, khususnya di Indonesia sudah cukup akuntabel. Namun dari unsur pengungkapan yang memperhatikan indeks carbon emission disclosurebelum sepenuhnya optimal. Hasil penelitianpenelitian terkait carbon emission disclosureini jugamenunjukkan inisiatif para pemilik perusahaan untuk mengungkapkan emisi karbon pada laporan tahunan perusahaannya. Perubahan ikliminformasi tersebut bertujuan untuk pengendalian risiko internal dan memberikanimage positifkepada publik. 


\section{DAFTAR PUSTAKA}

Astuti, Leni dan Setiawati, Erma. "Analisis Pengaruh Profitabilitas, Kebijakan Deviden, Kebijakan Hutang, Dan Kepemilikan Manajerial terhadap Nilai Perusahaan (Studi Empiris Pada Perusahaan Manufaktur Yang Terdaftar Di Bursa Efek Indonesia Tahun 2010-2012)". Seminar Nasional dan Call For Paper. Program Studi Akuntansi-FEB UMS, 2014

Belkaoni, Ahmed Riahi. Teori Akuntansi. Jakarta: Salemba Empat, 2000

Botosan, C.A. Disclosure Level and The Cost of Equity Capital. The Accounting Review Vol.7, No.3, July 1997 : 323-349, 1997

Campbell, D. Intra- and inter-sectoral effects in environmental disclosures: Evidence for legitimacy theory? Business Strategy and the Environment, 12(6), 357-371, 2003

Choi, Bo Bae, Doowon, Lee and Jim Psaros. "An Analysis of Australian Company Carbon Emission Disclosures.” Pasific Accounting Review Journal, Vol. 25, pp 58-79, 2013

Chu, Choi Ieng, Bikram Chatterjee and Alistair Brown. The current status of greenhouse gas reporting by Chinese companies. "Managerial Auditing Journal", Vol. 28 Iss 2 pp. $114-139,2012$

Cotter, J., Najah, M. and Wang, S. S. Standardized Reporting Of Climate Change Information In Australia., 2011

Cragg, Wesley., Schwartz, Mark S., Weitzner, David., Corporate Sosial Responsibility. New York: Routledge, 2016

Daniri, Mas Achmad. StandarisasiTanggungJawabSosial Perusahaan. SambutanMenteri NegaraLingkunganHiduppada Seminar Sehari "A Promise ofGold Rating: Sustainable CSR". Tanggal 23 Agustus2006.hal.3.diambildari www.menlh. go.id. Diaksespadatanggal 23 Mei 2015 
Darrough, M.N. "Disclosure Policy and Competition: Courtnot vs Bertrand.” The Accounting Review, Vol.68 No.3, pp. 534561,1993

Dwijayanti, S,P.F. Manfaat Penerapan Carbon Accounting di Indonesia. Jurnal Akuntansi kontemporer, Vol 3, No.1, hlm 79-92, 2011

Effendi, Muh.Arief. 2016. The Power of Good Corporate Governance TeoridanImplementasi. Jakarta: SalembaEmpat, 2016

Fajar, Mukti, Tanggung Jawab Sosial Perusahaan di Indonesia. Yogyakarta: Pustaka Pelajar, 2013

Febrianti, M, Faktor-Faktor yang Mempengaruhi Nilai Perusahaan pada Industri Pertambangan di Bursa Efek Indonesia. Jurnal Bisnis dan Akutansi, Vol.14 No.2, Agustus 2012, Hlm 141-156, 2012

Fitria, Soraya dan Hartanti, "Islam dan Tanggung Jawab Sosial: Studi Perbandingan Pengungkapan Berdasarkan Global Reporting Initiative Indeks dan Islamic Social Reporting Indeks". Simposium Nasional Akuntansi XIII. Purwokerto, 2010

Friedman, Milton, "The Social Responsibility of Business is to Increase its Profits", The New York Times Magazine, 1 September 1970, http://www.colorado.edu/ studenggroups/libertarians /issues/friedman-soc-respbusiness.html.

Ghomi \& Leung, An Empirical Analysis of The Determinants of Greenhouse Gas Voluntary Disclosure in Australia. Accounting and Finance Research, Vol. 2 No. 1, 110127,2013

Ghozali, Imam, Aplikasi Analisis Multivariate dengan Program IBM SPSS 21 . Cetakan VII. Semarang: Badan Penerbit Universitas Diponegoro, 2013

Ghozali, Imam dan Chariri, Anis, Teori Akuntansi. Badan Penerbit Universitas Diponegoro. Semarang, 2007 
Gray, et. al., Corporate Social and Environmental Reporting: A Review of Literature and a Longitudinal Study of UK Disclosure. Accounting, Auditing, and Accountability Journal Vol.8 No 2: 47-76, 1995

Gray, R, "Thirty Years of Social Accounting, Reporting, and Auditing: what (if anything) have we learnt?.'Business Ethics: A European Review, Vol. 10, No.1, pp. 9-15, 2001

Healy, Paul M., Krishna G. Palepu, "Information Asymmetry, Corporate Disclosure, and the Capital Markets: A Review of the Empirical Disclosure Literature", Journal of Accounting and Economics, 31 (1-3), 405-440, 2001

Ikhsan, Arfan, Sukma Lesmana dan Atma Hayat, Teori Akuntansi. Bandung: Citapustaka Media, 2015

Jannah, R. dan Muid, D,“Analisis Faktor-Faktor Yang Mempengaruhi Carbon Emission Disclosure Pada Perusahaan Di Indonesia.'Diponegoro Journal Of Accounting, Vol. 3, No. 2, pp. 1, 2014

Kardono, Memahami Perdagangan Karbon. Info PUSTANLING, Volume 12 No. 1, Hal 2-15, 2010

Kartini, Dwi, Corporate Social Responsibility: Tranformasi Konsep Sustainablity Management dan Implementasi di Indonesia. Bandung: Refika Aditama, 2013

Lorenzo, Jose-Manel Prado, Luiz Rodriguez-Dominguez, Isabel Gallego-Alvarez dan Isabel-Maria Garcia-Sanchez. Factors Influencing the Disclosure of Greenhouse Gas Emissions in Companies World-Wide. Journal of Management Decisions, Vol.47, pp.1133-1157, 2009

Meek, G.K., Clare, B. Roberts., Sidney. J. Gray, "Factors Influencing Voluntary An-nual Report Disclosure by U.S., U.K. and Continental European Multinational Corporations", Journal of International Business Studies, Vol. 26, No. 3, pp. 555-571. 1995 
Najah, M. M. S, "Carbon risk management, carbon disclosure and stock market effects: An international perspective.'Doctor of Philosophy, University of Southern Queensland, Australia, 2012

Pradini, H. S., "The Analysis of Information Content towards Greenhouse Gas Emissions Disclosure in Indonesia Companies". Fakultas Ekonomika dan Bisnis, Universitas Diponegoro, 2013

Putri, Hanni Chyntia Maita dan Surya Raharja. Pengaruh CSR terhadap Nilai Perusahaan dengan Kepemilikan Manajerial sebagai Variabel Moderating. "Diponegoro journal of accounting", Vol.2, No 3, Tahun 2013, Hal 1.

Rachman, Nurdizal M, Panduan Lengkap Perencanaan CSR. Jakarta: Niaga Swadaya, 2011

Safitri, Yancik dan Trisnadi Wijaya, Analisis Pengaruh Leverage Ratio, DPR, EPS dan Kepemilikan Manajerial terhadap Nilai Perusahaan. STIE MDP, 2015

Said, Achmad Lamo, Corporate Social Responsibility dalam Perspektif governance. Yogyakarta: V Budi Utama, 2015

Saka, Chika and Tomoki Oshika. "Disclosure effects, carbon emissions and corporate value". Management and policy journal, Vol.5 No.1, 2014.

Siswosoemarto, Rubijanto, Intelejen Ekonomi: Teori dan Aplikasi. Jakarta: PT Gramedia Pustaka Utama, 2012

Suhardjanto, Djoko dan Shinta Nugraheni, "Pengaruh Corporate Social Responsibility (CSR) Disclosure terhadap Nilai Perusahaan (Studi Empiris di Bursa Efek Indonesia". Jurnal Akuntansi., Volume 16, Nomor 2, Tahun 2012 Fakultas Ekonomi Universitas Tarumanagara, 2012

Sutarno, Sumber Daya Energi. Edisi 1, Cetakan ke-1. Yogyakarta: Graha Ilmu, 2013 
Uyar et, al, Association Between Firm : Evidence from Turkish Listed Companies. Intangible Capital, Vol. 9(4), 1080-1112, 2013

Wibisono, Yusuf, Membedah Konsep dan Aplikasi Corporate Social Responsibilitie. Cetakan ke-2. Gresik: Fascho Publishing, 2007

Wilmshurst, T. D., \& Frost, G. R, Corporate environmental reporting: a test of legitimacy theory. Accounting, Auditing \& Accountability Journal, 13 (1), 10-26, 2000

Wolfe, Alan. "The Modern Corporation: Private Agent or Public Actor?", Washington and Lee Law Review 50, hal. 1683S, 1993 
